\title{
ON A PROBLEM OF UNIVALENCE OF FUNCTIONS SATISFYING A DIFFERENTIAL INEQUALITY
}

\author{
SuKHWINDER SINGH, Sushma GUPTA AND SuKHJIT SINGH
}

Abstract. Let $\mathcal{H}_{\alpha}(\beta)$ denote the class of normalized functions $f$, analytic in the unit disc $E$, which satisfy the condition

$$
\operatorname{Re}\left[(1-\alpha) f^{\prime}(z)+\alpha\left(1+\frac{z f^{\prime \prime}(z)}{f^{\prime}(z)}\right)\right]>\beta, z \in E,
$$

where $\alpha$ and $\beta$ are pre-assigned real numbers. H. S. Al-Amiri and M. O. Reade, in 1975, have shown that for $\alpha \leqslant 0$ and also for $\alpha=1$, the functions in $\mathcal{H}_{\alpha}(0)$ are univalent in $E$. In 2005, V. Singh, S. Singh and S. Gupta proved that for $0<\alpha<1$, functions in $\mathcal{H}_{\alpha}(\alpha)$ are also univalent. In the present note, we establish that functions in $\mathcal{H}_{\alpha}(\beta)$ are univalent for all real numbers $\alpha$ and $\beta$ satisfying $\alpha \leqslant \beta<1$ and that the result is sharp in the sense that the constant $\beta$ cannot be replaced by any real number less than $\alpha$.

Mathematics subject classification (2000): 30C45, 30C50.

Key words and phrases: univalent function, convex function, differential subordination.

\section{REFERENCES}

[1] O. P. Ahuja, H. Silverman, Classes of functions whose derivatives have positive real part, J. Math. Anal. Appl., 138, (2) (1989), 385-392.

[2] H. S. AL-AMIRI, M. O. READE, On a linear combination of some expressions in the theory of univalent functions, Monatshefto für mathematik, 80, (1975), 257-264.

[3] S. S. MiLleR, Differential Inequalities and Carathéodory functions, Bull. Amer. Math. Soc., 81, (1975), 79-81.

[4] K. Noshiro, On the theory of schlicht functions, J. Fac. Sci., Hokkaido Univ., 2, (1934-35), 129-155.

[5] V. Singh, S. Singh AND S. GUPTA, A problem in the theory of univalent functions, Integral Transforms and Special Functions, 16, (2) (2005), 179-186.

[6] S. E. WARCHAWSKI, On the higher derivatives at the boundary in conformal mappings, Trans. Amer. Math. Soc., 38, (1935), 310-340. 